\title{
HABERMAS E A RELIGIÃO
}

\author{
HABERMAS AND RELIGION
}

Julio Tomé*

\section{RESUMO}

Neste trabalho tem-se por objetivo apresentar a teoria habermasiana da religião na esfera pública. Procura-se entender as relações dos cidadãos religiosos e não religiosos, no pensamento de Habermas, em uma sociedade democrática laica e que garante a livre expressão religiosa, sem que a cooperação social e os pressupostos democráticos sejam afetados. Assim como, procura-se entender qual o papel das religiões e das tradições seculares nos Estados modernos de hoje. Para tanto, apresenta-se o papel da secularização dos Estados modernos; o papel que o direito desempenha no processo de mudança de organização social a mudança de um Estado confessional para um Estado laico; assim como o papel comunicativo dos cidadãos e das religiões, e como as religiões podem influenciar a esfera pública, para que esta seja uma expressão de seus ideais. Adentra-se na, já clássica, discussão Rawls/Habermas acerca do papel da religião na esfera pública, em que se apresentam as críticas de Habermas ao pensamento rawlsiano, a respeito da necessidade da tradução de argumentos religiosos para uma linguagem neutra e razoável na esfera pública, sobre o qual, deve-se salientar que não é objetivo defender uma ou outra perspectiva, mas sim apenas expor as ideias de Habermas e Rawls.

PALAVRAS-CHAVE: Habermas. Secularização. Religião. Estado laico. Esfera pública.

\section{ABSTRACT}

In this work the objective is to present the Habermasian theory of religion in the public sphere. It is sought to understand the relations of religious and non-religious citizens, in Habermas's thinking, in a secular democratic society and that guarantees free religious expression, without social cooperation and democratic presuppositions being affected. In the same way, we try to understand the role of religions and secular traditions in today's modern states. For that, the role of secularization of modern states is presented; the role that law plays in the process of changing social organization - the change from a confessional state to a secular state; as well as the communicative role of citizens and religions and how religions can influence the public sphere so that it is an expression of their ideals. It is introduced in the already classic Rawls/Habermas discussion about the role of religion in the public sphere, on which Habermas's criticisms of Rawlsian thought are presented, on the need to translate religious arguments into a neutral and reasonable language in the public sphere, on which it should be pointed out that one does not aim to defend one or another perspective, but rather one wishes only to expose the ideas of Habermas and Rawls.

KEYWORDS: Habermas. Secularization. Religion. Secular state. Public sphere.

\footnotetext{
* Bacharel e Licenciado em filosofia pela Universidade Federal de Santa Catarina. Mestre em Filosofia da mesma universidade (PPGFIL/UFSC). Atualmente é doutorando em filosofia, na área de ética e filosofia política no PPGFIL/UFSC, sob a orientação do prof. Dr. Denilson L. Werle. E-mail: juliohc7@ @otmail.com.
} 


\section{INTRODUÇÃO}

Para cumprir seus objetivos - apresentar o pensamento habermasiano acerca da religião nas sociedades modernas -, divide-se este trabalho em três seções. Na primeira o objetivo é apresentar aquilo que Habermas chama de processo de secularização dos estados modernos, isto é, a passagem dos Estados confessionais para Estados laicos e neutros nas questões de fé. Estados nos quais o poder agora não mais poderia ser justificado pelo poder religioso, mas sim por uma base de justificação pública (neutra), como por exemplo, pelo Direito. Assim, adentra-se a segunda seção, que tem por objetivo primordial apresentar como o direito, por meio da divisão entre autonomia privada e pública, consegue garantir as liberdades políticas e de comportamento dos cidadãos e das cidadãs do Estado, uma vez que o Direito (moderno) acaba, de certa maneira, substituindo o papel da Igreja no processo de institucionalização de comportamento. Dessa maneira, abre-se caminho para as discussões da terceira e derradeira seção deste trabalho, na qual se discute o papel da religião na esfera pública, e objetiva-se apresentar a perspectiva habermasiana em contraste com a teoria da John Rawls, tendo em vista o importante debate travado entre o filósofo alemão e o filósofo estadunidense, no século XX, acerca da traduzibilidade dos argumentos religiosos na esfera pública.

\section{O PROCESSO DE SECULARIZAÇÃO}

Habermas afirma em Fé e saber (2013) que a palavra "secularização" teve em princípio um significado jurídico de uma transferência compulsória dos bens da Igreja para o poder público secular. Significado que foi transmutado para o surgimento da modernidade cultural e social, como um todo e gerou, como consequência, que as apreciações opostas têm sido associadas ao conceito de secularização, em que, por um lado, os modos de pensar e as formas de vida religiosas são substituídos por equivalentes racionais (domesticação da autoridade eclesiástica); e, por outro lado, as formas modernas de vida e pensamento são desacreditadas como bens furtados ilegitimamente (ato de apropriação ilícita).

Nesses dois lados, o modelo de substituição é uma interpretação otimista e progressista para uma modernidade desencantada; enquanto a interpretação da apropriação forçada sugere a ruína de uma modernidade desamparada. Mas as duas interpretações cometem o mesmo erro, segundo o autor: "[...] elas consideram a secularização um jogo de 
soma zero entre, de um lado, as forças produtivas da ciência e da técnica, lideradas pelo capitalismo e, de outro, os poderes conservadores da religião e da Igreja. [...]" (HABERMAS, 2013, p. 6), e por meio dessa interpretação, tem-se a ideia de que um só pode vencer à custa do outro, e isso segundo as regras liberais de um jogo que favorece as forças motrizes da modernidade. Para Habermas, essa imagem não é adequada, pois não leva em conta o papel civilizador do senso comum democraticamente esclarecido que funciona como um terceiro partido entre a ciência e a religião. Pois, "[...] este serve aos indivíduos como orientação para a vida cotidiana nos estados democráticos liberais [...]" (PINZANI, 2009b, p. 121).

Para Habermas, é pós-segunda-guerra, junto com a modernização social, que ocorreu uma onda de secularização na Europa ${ }^{1}$ - com exceção da Polônia e da Irlanda - sendo que havia, ao mesmo tempo, “[...] as regulamentações liberais do aborto, com a recusa incondicional da tortura, com a equiparação das orientações sexuais e com a paridade de conúbios homossexuais e, em geral, com o acento nos direitos e não nos bens coletivos [...]" (HABERMAS, 2007, p. 131); e o aumento da importância das religiões no contexto político.

Segundo o filosofo alemão, no Ocidente, por meio desse processo, as orientações valorativas conflitantes - "God, Gay and Guns" - acabam por se sobrepor aos conflitos aparentemente mais sólidos. Habermas, então, questiona até que ponto a separação entre Igreja e Estado pode influenciar no papel a ser desempenhado pelas tradições e comunidades religiosas, na esfera pública política (EPP) e na sociedade civil, isto é, na formação política da opinião e da vontade dos cidadãos.

No Estado secular, o exercício do poder tem que ser transposto para uma base não mais religiosa, e a constituição democrática tem que preencher a lacuna de legitimação aberta pela neutralização do poder do Estado. O mesmo é válido para o direito moderno positivo que só pode apresentar-se enquanto ordem normativa quando justificado sob um sistema coerente que possibilita a produção de normas segundo um procedimento constituinte que dá os direitos simétricos de cidadãos livres e iguais que atribuem uns aos outros e é determinado por regras precisas (PINZANI, 2011, p. 141). Para Habermas:

\footnotetext{
${ }^{1}$ Para Habermas (2007, p. 133-34), os Estados Unidos da América, foram os pioneiros na questão de liberdade religiosa apoiada no respeito recíproco da liberdade de religião do outro. "[...] O grandioso artigo n ${ }^{\circ} 16$ da Bill of Rights proclamado na Virgínia, em 1776, constitui o primeiro documento de uma liberdade de religião garantida como um direito fundamental, que os cidadãos de uma comunidade democrática se concedem mutuamente independentemente dos limites estabelecidos pelas diferentes comunidades de fé [...]".
} 
[...] os cidadãos devem respeitar-se reciprocamente como membros de sua respectiva comunidade política, dotados de iguais direitos, apesar de seu dissenso em questões envolvendo convicções religiosas e visões de mundo; sobre esta base de uma solidariedade de cidadãos do Estado, eles devem procurar, quando se trata de questões disputadas, um entendimento mútuo motivado racionalmente, ou seja, eles são obrigados a apresentar uns aos outros, bons argumentos. [...] (HABERMAS, 2007, p. 137).

A base para referência do uso público da razão só é obtida depois da diferenciação de uma associação de cidadãos livres e iguais que se determinam a si mesmos e que justificam, uns aos outros, seus posicionamentos políticos na base dos princípios constitucionais, a autocompreensão do Estado de direito democrático forma-se por meio da tradição filosófica que apela exclusivamente para uma razão "natural", isto é, de que os argumentos públicos, conforme suas pretensões, são acessíveis da mesma maneira a todas as pessoas. E com a ideia de uma razão humana comum constitui-se a base epistêmica para a justificação de um poder do Estado secular que independe de legitimações religiosas. Ao mesmo tempo, permite, segundo Habermas, pensar a separação entre Igreja e Estado ao nível institucional. "O direito fundamental da liberdade de consciência e de religião constitui a resposta política adequada aos desafios do pluralismo religioso [...]” (HABERMAS, 2007, p. 136).

Para Habermas, por meio do pensamento "pós-metafísico" adotado para tratar da religião, manifesta-se uma pressuposição cognitiva para a disposição de cooperação que se espera dos cidadãos seculares. Essa pressuposição corresponde ao enfoque epistêmico que os cidadãos seculares precisam assumir quando estão dispostos a aprender com contribuições de seus concidadãos religiosos, sobre as quais, conforme os casos, pode ser traduzido para uma linguagem acessível em geral. O uso público da razão, introduzido pelo pensamento "pósmetafísico" depende de pressuposições cognitivas e tem consequências interessantes e discrepantes que remete ao fato de o Estado constitucional democrático representar uma forma de governo pretensiosa do ponto de vista epistêmico e sensível à verdade. E, com a polarização das cosmovisões de uma comunidade que se divide em dois campos, demonstra que a integração política pode ser ameaçada a partir do momento que um número muito elevado de pessoas não consegue atingir os standards do uso público da razão.

Por meio do pluralismo religioso, da ascensão das ciências modernas, e da disseminação do direito positivo e da moral social profana, houve uma "modernização" da consciência religiosa, que vem desde a Reforma e do Iluminismo. Com isso, Habermas afirma que os cidadãos religiosos precisam: $\mathrm{i}$ - encontrar um enfoque epistêmico que seja aberto às visões de mundo e às religiões estranhas, que até então só conheciam por meio do intermédio 
do universo discursivo de suas religiões; ii - precisam também encontrar um enfoque epistêmico aberto ao sentido próprio do conhecimento secular e ao monopólio do saber dos especialistas, institucionalizados socialmente; iii - também precisam de um enfoque epistêmico para encarar os argumentos seculares que gozam de precedência na arena política. "Tal trabalho da autorreflexão hermenêutica tem de ser realizado pelo ângulo de uma autopercepção religiosa [...]” (HABERMAS, 2007, p. 156). Sob a luz de condições modernas da vida, os novos enfoques epistêmicos são aprendidos como resultados de uma reconstrução de verdades de fé transmitidas, que se tornam evidentes para os próprios participantes.

A consciência secular que vive em uma sociedade pós-secular reflete-se filosoficamente na figura do pensamento pós-metafísico ${ }^{2}$. Sendo que, “em tom pósmetafísico, a filosofia não pode mais desempenhar o papel de discurso fundacional, mas, sim, assumir seu lugar como uma das vozes que compõem a sinfonia dos discursos da sociedade democrática [...]” (ZABATIERO, 2010, p. 21). No pensamento pós-metafísico, constitui-se uma contrapartida secular para a consciência religiosa que se fez reflexiva, e que se delimita quando, por meio de premissas agnósticas, se abstém de emitir juízos sobre verdades religiosas em uma delimitação que diz respeito estritamente à questão de fé e saber; e contra uma concepção cientificista da razão e contra a exclusão das doutrinas religiosas da genealogia da razão.

Em síntese, o pensamento pós-metafísico assume uma dupla atitude perante a religião, porquanto ele é agnóstico e está, ao mesmo tempo, disposto a aprender. Ele insiste na diferença entre certezas de fé e pretensões de validade contestáveis em público; abstém-se, porém, de adotar uma presunção racionalista, a qual o levaria a pretender decidir por si mesmo sobre o que é racional e o que não é nas doutrinas religiosas. Entretanto, os conteúdos dos quais a razão se apropria por tradução não constituem necessariamente uma perda para a fé. Além disso, uma apologia da fé, elaborada com meios filosóficos, não é tarefa da filosofia, que continua agnóstica. (HABERMAS, 2007, p. 162).

Para uma garantia simétrica da liberdade religiosa, o caráter secular do Estado constitui uma condição necessária, mas não suficiente, pois as próprias partes envolvidas têm que chegar a um acordo sobre a separação entre direito positivo e o exercício da religião da liberdade negativa em que ninguém é obrigado a seguir a religião do outro. E a proteção do

\footnotetext{
${ }^{2}$ Importante salientar que a relação direito e moral é interpretada pela ideia de um nível pós-metafísico em que tanto as regras morais como as jurídicas diferenciam-se da eticidade tradicional, e colocam-se como dois diferentes tipos de normas de ação, e que além de estarem lado a lado, completam-se. Pois, "[...] por um lado, o direito não pode contrariar a moral, e, por outro lado, não pode ser subordinado no sentido de a moral ser hierarquicamente superior. [...]" (VOLPATO DUTRA; LOIS, 2007, p. 242).
} 
princípio de tolerância se dá por argumentos convincentes e aceitáveis, de modo igual, por todas as partes, pois por meio da criação de regras equitativas pressupõe-se que os participantes aprendam a assumir as perspectivas uns dos outros.

No pensamento habermasiano, conforme questões existencialmente relevantes vão para a agenda política, os cidadãos trabalham as dissonâncias do conflito público de opiniões e têm a experiência do pluralismo de visões de mundo, onde, conforme aprendem a lidar com esse fato, reconhecem o que significam, em uma sociedade "pós-metafísica", as condições seculares da tomada de decisões que foram estabelecidas pela constituição. Pois, “[...] trata-se de uma sociedade pluralista, que já não dispõe de concepções éticas compartilhadas e já não pode apelar para a tradição na tentativa de justificar normas morais específicas [...]" (PINZANI, 2005, 362).

Salienta-se que a concepção de tolerância de sociedades pluralistas de constituição liberal, no pensamento de Habermas, não exige apenas dos crentes que entendam que precisam contar com a continuidade de um dissenso, mas também se exige esse posicionamento dos descrentes no relacionamento com os religiosos. O que implica que o cidadão, sem tino para a religião, recebe uma convocação, que para Habermas não é nada trivial, para determinar de maneira autocrítica a relação entre fé e conhecimento na base do conhecimento geral do mundo. Donde, para ser "sensata", a expectativa não pode simplesmente convencionar as convicções religiosas com um status epistêmico como sendo pura e simplesmente irracionais, na perspectiva do conhecimento secular-profano.

\section{SOBRE O DIREITO E A COMUNICAÇÃO}

Tem-se assim, com o processo de secularização, que o Direito (moderno) acaba, de certa maneira, substituindo o papel da Igreja no processo de institucionalização de comportamento. Garante-se ao indivíduo a liberdade de consciência, de pensamento, de credo etc., contudo, conforme o direito assegura a autonomia privada e a autonomia pública, o direito operacionaliza a tensão entre facticidade e validade. O direito conduz o arbítrio dos interesses dos sujeitos que se orientam pelos trilhos de leis contingentes, que tornam compatíveis iguais liberdades subjetivas de ação, por um lado e, por outro, o sistema mobiliza e reúne as liberdades comunicativas de civis que estão, supostamente, orientados pela ideia de "bem comum", na prática da legislação. O que faz com que, novamente, se irrompa a tensão entre facticidade e validade, pois em primeira vista os direitos políticos fundamentais 
precisam institucionalizar o uso público das liberdades comunicativas na forma de direitos subjetivos. A consequência é que os direitos de comunicação e participação têm que ser formulados em uma linguagem que permita aos sujeitos autônomos escolher se e como vão fazer uso deles. Com o conceito de poder comunicativo, atinge-se apenas o surgimento de um poder político que se estende ao emprego do poder administrativo e à concorrência pelo acesso ao sistema político.

O direito constitui um poder político, e o contrário também é verdadeiro, segundo o pensamento habermasiano, gerando um nexo entre eles que abre a possibilidade de uma instrumentalização do direito para o emprego estratégico do poder. Mas, para gerar a ideia de um Estado de direito, exige-se uma organização do poder público que obriga o poder político a se legitimar pelo direito legitimamente instituído, sendo que os códigos de direito e de poder precisam completar-se mutuamente, para que assim possam preencher suas funções. Mas as relações de troca entre esses poderes se alimentam de uma normatização legítima do direito que é ligada a formação do poder comunicativo, o que implica uma diferenciação do poder político.

Assim, dado que os direitos humanos e o princípio de soberania do povo justificam a ideia do direito moderno, pois suas ideias se somam aos conteúdos que sobrevivem ao crivo da fundamentação pós-tradicional, os direitos humanos são a expressão de uma autodeterminação moral, e a soberania do povo autorrealização ética, sobre a qual, como consequência, tem-se a interligação entre soberania do povo e direitos humanos, que surge da cooriginalidade da autonomia política e da autonomia privada.

No princípio de soberania popular, o direito subjetivo à participação vai de encontro à possibilidade jurídico-objetivo de uma prática institucionalizada de autodeterminação dos cidadãos. E por meio desse princípio forma-se o espelho entre o sistema de direitos e a construção de um Estado de Direito. E assim:

[...] interpretado pela teoria do discurso (a), o princípio da soberania popular implica: (b) o princípio de ampla garantia do indivíduo, proporcionada através de uma justiça independente; (c) os princípios da legalidade da administração e do controle judicial e parlamentar da administração; (d) o princípio de separação entre sociedade e estado, que visa impedir que o poder social se transforme em poder administrativo sem passar antes pelo filtro da formação comunicativa do poder. (HABERMAS, 1997a, p. 212-3).

Segundo a teoria do discurso, o princípio da soberania do povo tem como significado que todo poder político é deduzido do poder comunicativo dos cidadãos. E o exercício do 
poder político se legitima por meio das leis que os cidadãos criam para si mesmos, com a formação estruturada discursivamente da opinião e da vontade. Já, quando o poder de soberania popular é visto sob o ângulo do poder, ele exige a transmissão de competência legislativa para a totalidade dos cidadãos, pois são os únicos capazes de gerar o poder comunicativo de convicções comuns, nas quais, as decisões fundamentadas e obrigatórias sobre políticas e leis exigem consultas e tomadas de decisão face to face, por um lado, e que nem todos os cidadãos possam se 'unir' no nível de interações simples e diretas, para uma prática exercitada em comum, por outro. Sendo a solução o princípio parlamentar da criação de corporações deliberativas representativas.

Salienta-se que em Direito e democracia, Habermas afirma que a formação política da opinião e da vontade precisa esclarecer três questões: $\mathrm{i}$ - a possibilidade de harmonizar entre si preferências concorrentes, ponto que subjaz à formação do compromisso; ii - a questão ético-política da formação de identidade pessoal e dos ideais que realmente se deseja alimentar; iii - assim como a questão prático-moral referente àquilo que se faz para buscar sobre o modo de agir para ser justo.

A formação política da vontade visa a uma legislação, pois ela interpreta e configura o sistema de direitos que os cidadãos reconhecem mutuamente por meio das leis, e porque o poder organizado do Estado só pode ser organizado e dirigido por meio de leis, “[...] o procedimento democrático da legislação depende, por sua vez, de cidadãos ativos, cujas motivações não podem ser impostas juridicamente." (PINZANI, 2011, p. 140). As leis formam a base para pretensões jurídicas individuais, que resulta na garantia dos caminhos do direito e do princípio da garantia de uma proteção jurídica individual ampla.

[...] durante o processo de formação política da opinião e da vontade, o poder da maioria transforma-se em repressão quando uma maioria que utiliza argumentos religiosos nega às minorias seculares ou aos que são de outras denominações a possibilidade de reproduzir discursivamente as justificações que lhe são devidas. O procedimento democrático extrai sua força de legitimação de seu próprio caráter deliberativo e da inclusão de todos os participantes; pois é sobre esse caráter que se fundamenta a suposição, fundamentada, dos resultados racionais in the long run (no longo prazo). (HABERMAS, 2007, p. 152).

Para Habermas, a constituição do Estado liberal basta por si mesma para se legitimar, e isso se dá pois dispõe de um acervo cognitivo de argumentos que independe das tradições religiosas e metafísicas. Mas a dúvida permanece no ponto de vista motivacional, pois “[...] Habermas admite a importância das bases pré-políticas da motivação dos cidadãos, a qual se 
encontra amplamente vinculada aos valores de doutrinas abrangentes religiosas [...]" (SOUZA, 2009, p. 256) e afirma que os pressupostos normativos do Estado são mais exigentes em relação ao papel dos cidadãos enquanto autores do direito, do que em relação aos cidadãos enquanto destinatários do direito. Entretanto, segundo Habermas, dos destinatários espera-se apenas que não ultrapassem os limites legais, isto é, que obedeçam às leis obrigatórias de liberdade; enquanto dos autores espera-se que exerçam ativamente seus direitos de comunicação e participação, tendo como vista o bem comum. É essencial para a sobrevivência da democracia que as virtudes políticas sejam cobradas, pois elas fazem parte da socialização e da familiarização com as práticas e os modos de pensar de uma cultura política liberal.

Para Habermas, os motivos que levam os cidadãos a participarem da formação da opinião e da vontade políticas nutrem-se de projetos éticos e de formas culturais de vida, mas isso não significa ignorar que as práticas democráticas se desenvolvem, também, em sua própria dinâmica política. O Estado democrático de direito não garante apenas as liberdades negativas, mas quando permite as liberdades comunicativas, para Habermas, está incentivando a participação dos cidadãos nos debates públicos sobre temas que dizem respeito a todos, pois é uma prática comunicativa originária do próprio processo democrático que só pode ser exercida em comum e na qual se discute o verdadeiro entendimento da constituição, é o "vínculo unificador", que segundo o pensamento habermasiano estaria faltando.

Assim, na perspectiva de uma democracia liberal, o poder político consegue disfarçar sua essência dominativa por meio de uma ligação, juridicamente cogente, aos princípios de exercícios do poder suscetíveis de um assentimento geral. Os conflitos existenciais sobre os valores entre comunidades de fé não se prestam a compromissos, eles só podem ser desamarrados por uma despolitização que lança mão de princípios constitucionais ante o pano de fundo de um consenso que se supõe ser comum. Para Habermas, sem um laço unificador de uma solidariedade, que não pode ser imposta por normas do direito, os cidadãos não conseguem se entender como participantes, com os mesmos direitos, de uma prática comum que possibilita a formação da opinião e da vontade, em que os cidadãos devem uns aos outros argumentos que justifiquem seus posicionamentos políticos. Essa reciprocidade das expectativas dos cidadãos do Estado diferencia uma comunidade liberal de uma comunidade segmentada por visões de mundo.

A natureza secular da sociedade não apresenta nenhuma deficiência interna, seja referente ao sistema político em si, e que possa pôr em risco a autoestabilização sob o ponto 
de vista cognitivo ou motivacional. Mas isso não impede que haja o enfraquecimento do vínculo democrático, esgotando a solidariedade de que o Estado democrático depende. O que, nesse caso, implicaria a situação visada por Böckenförde ${ }^{3}$ que teria como consequência que as esferas privadas são cada vez mais pensadas para a obediência de mecanismos de ação voltados para o sucesso e para as próprias preferências, gerando assim um processo de individualização com pressupostos meritocráticos, quando cada pessoa é responsável por seu sucesso e deixa de olhar para a história e circunstâncias sociais e culturais. Perde-se a função de formação democrática da opinião e da vontade, aumentando assim o processo de "privatismo" do cidadão.

Contudo, Habermas entende a secularização da sociedade como um processo comum de aprendizagem, em que ambos os lados têm condições de levar a sério, em público, as respectivas contribuições para temas controversos. "A verbalização do sagrado traduz uma laicização racional do vínculo social primitivo na força ilocucionária da linguagem profana, cuja autoridade está ligada à força não coerciva, motivada racionalmente, do melhor argumento [...]" (ARAUJO, 2009a, p. 236).

\section{A RELIGIÃo NA ESFERA PÚBLICA}

Segundo Habermas, quando se dá às religiões a possibilidade de exercer por meio da esfera pública política sua própria influência sobre a sociedade como um todo, a expectativa normativa com a qual a comunidade religiosa se vê confrontada pelo Estado liberal confundese com seus próprios interesses. Entretanto, não se pode acabar com os espaços religiosos na esfera pública. "[...] a posição de Habermas sobre o papel da religião na esfera pública pode ser vista como um convite à prudência e à compreensão recíproca - e verossimilmente [...]” (PINZANI, 2009a, p. 213).

Para Habermas, a neutralidade ideológica do poder do Estado, que é o responsável por garantir as mesmas liberdades éticas para todos os cidadãos, tendo como pano de fundo a noção de Estado laico, é incompatível com a generalização de uma visão de mundo secularizada, sendo que o papel dos cidadãos secularizados não lhes permite, nem em princípio, contestar o potencial de verdade das visões religiosas de mundo, nem negar aos

\footnotetext{
${ }^{3}$ Que a transformação dos cidadãos de sociedade liberais prósperas e pacíficas em mônadas isoladas que usam entre si seus direitos subjetivos apenas como armas. Mercados que não podem ser democratizados assumem progressivamente funções de regulação em áreas da vida que haviam sido mantidas coesas de maneira normativa, seja politicamente ou de formas pré-políticas de comunicação.
} 
concidadãos religiosos o direito de contribuir para os debates públicos servindo-se de uma linguagem religiosa. Segundo o pensamento habermasiano, então, “[...] uma cultura política liberal pode até esperar dos cidadãos secularizados que participem de esforços para traduzir as contribuições relevantes em linguagem religiosa para uma linguagem que seja acessível publicamente" (HABERMAS; RATZINGER, 2007, p. 57).

Habermas acredita ser "um fardo pesado demais" para os religiosos eles terem que traduzir seus posicionamentos políticos na esfera pública para uma linguagem secular, ou como diria Rawls, para uma linguagem neutra e razoável. O filósofo alemão, diferentemente do filósofo estadunidense, defende a não necessidade de tradução dos argumentos religiosos nas esferas públicas informais. Entretanto, como é apresentado por Habermas (2007), os religiosos devem aceitar que na esfera pública formal só contam os argumentos seculares.

Segundo o autor, conforme o pressuposto do proviso rawlsiano, por meio do princípio de separação da Igreja com o Estado, os políticos e os funcionários estatais devem formular e justificar as leis, decisões judiciais etc., em uma linguagem acessível a todos os cidadãos. Porém, na esfera pública política, os cidadãos, os partidos políticos e candidatos, as organizações sociais e as igrejas não estão em uma reserva tão estrita. E não se podem confundir os argumentos em prol de um papel político da religião que por um lado são inconciliáveis com o caráter secular do Estado constitucional e, por outro lado, que constituem objeções justificadas contra uma compreensão secularista da democracia e do Estado constitucional.

O princípio da separação entre Igreja e Estado exige das instituições estatais rigor extremo no trato com as comunidades religiosas; parlamentos e tribunais, governo e administração ferem o mandamento da neutralidade a ser mantida quanto a visões de mundo quando privilegiam um dos lados em detrimento de um outro. De outro lado, no entanto, a exigência laicista de que o Estado deve (em consonância com a liberdade de religião) abster-se de toda política que apoia ou coloca limites à religião enquanto tal constitui uma interpretação por demais estreita desse princípio. Em que pese isso, a rejeição do secularismo não deve abrir as portas para revisões que venham a anular a separação entre Igreja e Estado. (HABERMAS, 2007, p. 140).

Assim, contra o proviso rawlsiano, Habermas afirma que pode-se objetar que muitos cidadãos religiosos não poderiam concretizar a divisão artificial da sua própria consciência sem colocar em jogo sua própria existência piedosa. Há também a objeção que se refere ao papel integral que a religião assume na vida das pessoas crentes em que os cidadãos religiosos têm “[...] sua concepção de justiça, fundada na religião, lhes ensina o que é politicamente correto ou incorreto, de tal sorte que eles são incapazes de discernir entre razões seculares e 
razões 'pull"' (HABERMAS, 2007, p. 144-145). E, para Habermas, se se aceitar tal objeção, não se pode esperar que o Estado liberal, que protege as formas de vida religiosas por meio do princípio de liberdade de religião, possa esperar que todos os crentes fundamentem seus posicionamentos políticos deixando inteiramente de lado suas convicções religiosas ou metafísicas sobre o mundo. "Tal exigência estrita só pode ser dirigida aos políticos que assumem mandatos públicos ou se candidatam a eles e que, por esse fato, são obrigados a adotar a neutralidade no que tange às visões de mundo." (HABERMAS, 2007, p. 145).

Para Habermas a neutralidade do exercício do poder constitui uma pressuposição institucional necessária para uma garantia simétrica da liberdade religiosa e salienta que “[...] o significado correto de neutralidade liberal é a de que os princípios políticos não devem favorecer ou promover nenhuma doutrina abrangente particular sujeita ao desacordo razoável entre os membros de uma sociedade. [...]" (ARAUJO, 2010, p. 105). É por meio do consenso constitucional que se atinge o princípio de separação entre Igreja e Estado. Entretanto, Habermas afirma que a transposição do princípio de cunho institucional para posicionamentos de organizações e de cidadãos na EPP constitui uma generalização excessiva. E o poder secular do Estado não implica para os cidadãos religiosos, em particular, obrigação pessoal e imediata de complementar suas convicções religiosas, publicamente exteriorizadas, e de traduzi-las por meio de equivalentes em uma linguagem acessível a todos.

O filósofo alemão afirma que o Estado liberal não pode obrigar os cidadãos religiosos a levarem a cabo, na Esfera Pública Política, uma separação estrita entre argumentos religiosos e não religiosos, pois essa tarefa pode consistir em um ataque à sua identidade nacional, e consequentemente à neutralidade do Estado. O Estado liberal não pode transformar a separação institucional da Igreja e do Estado em uma sobrecarga mental e psicológica insuportável para os religiosos, entretanto, esses cidadãos devem reconhecer que o princípio do exercício político é neutro naquilo se refere às visões de mundo, e como consequência deve-se aceitar que na esfera pública formal - parlamentos, tribunais etc. - só contam argumentos seculares ${ }^{4}$. No pensamento habermasiano, conforme os cidadãos religiosos participam de discussões públicas e reconhecem a "reserva de tradução institucional”, eles não precisam dividir suas identidades em partes privadas e públicas.

E, como consequência, eles (os religiosos) deveriam poder expressar e fundamentar suas convicções em uma linguagem religiosa mesmo quando não encontram tradução secular. “[...] na esfera pública as controvérsias e as negociações culturais entre uma variedade de

\footnotetext{
${ }^{4}$ Neste ponto, recomenda-se a leitura do texto de Coelho (2015).
} 
públicos em torno da validade de certas proposições têm lugar e se tornam visíveis [...]" (MONTERO, 2015, p. 213). E, conforme os cidadãos religiosos "[...] podem manifestar-se numa linguagem religiosa apenas sob a condição do reconhecimento da 'ressalva de uma tradução institucional', eles podem, apoiados na confiabilidade das traduções cooperativas de seus concidadãos, entender-se como participantes do processo de legislação, mesmo que os argumentos decisivos nesse processo sejam seculares" (HABERMAS, 2007, p. 148).

Segundo Habermas, o Estado Liberal possui um interesse na liberação das vozes religiosas no âmbito da esfera pública política, bem como na participação política de organizações religiosas, não podendo desencorajar os crentes e as comunidades religiosas de se manifestarem de forma política, pois ao fazer isso o Estado liberal poderia estar privando a sociedade a recursos importantes para a criação do sentido. Habermas acredita que os crentes de outros credos, assim como os cidadãos seculares, podem aprender algo com as contribuições religiosas. Para Habermas, os limiares institucionais que se colocam entre uma EPP "selvagem” e as corporações estatais criam certos filtros que são cunhados para dar vazão a contribuições seculares.

\section{CONSIDERAÇÕES FINAIS}

Em uma democracia constitucional liberal, tem-se como pressuposto que as pessoas, enquanto cidadãs de um Estado democrático de direito, são livres para perseguirem seus objetivos de vida, têm liberdade de escolher seus valores morais, suas religiões, podendo mudá-las sempre que quiserem ou acharem necessário, sem que isso acarrete em qualquer ônus ou bônus naquilo que tange aos direitos políticos ou sociais. Há também como pressuposto a igual liberdade de pensamento e associação, assim como o direito à liberdade de culto e de expressão.

Assim, tendo em vista o pensamento habermasiano, sabe-se que o autor reconhece que as múltiplas concepções de vida boa - pressupostas pelas sociedades liberais modernas de hoje - podem fazer com que a integração política seja solapada, como visto anteriormente. Dessa forma, visando a evitar a desintegração política (e da cooperação social), Habermas afirma que o pensamento pós-metafísico deve assumir uma dupla atitude perante a religião de agnosticismo e, também, de disposição para o aprendizado.

Jürgen Habermas afirma que o Estado moderno, por meio de sua constituição e suas pretensões de neutralidade, é um Estado pretensioso do ponto de vista epistêmico e sensível à 
verdade. Naquilo que tange ao papel dos cidadãos e das cidadãs religiosos, tem-se que eles e elas devem encontrar um enfoque epistêmico que (i) é aberto às múltiplas visões de mundo; (ii) aberto ao próprio conhecimento secular - com o monopólio do saber especializado; (iii) para, assim, encarar os argumentos seculares que gozam de precedência na arena política.

Habermas não tem uma postura contrária à secularidade do Estado, pelo contrário, este parece ser um ponto central do pensamento habermasiano. Contudo, segundo o filósofo alemão, a secularidade é uma condição necessária, mas não suficiente para as garantias simétricas da liberdade religiosa. Isto se dá, pois, segundo o pensamento de Habermas, a tolerância não exige apenas que os crentes estejam dispostos ao debate - colocando suas verdades e dogmas à avaliação de validade dos demais cidadãos e cidadãs - mas, também, que os descrentes (cidadãos e cidadãs seculares) estejam dispostos a tal.

Habermas, portanto, entende a secularização da sociedade moderna como um processo comum de aprendizagem em que ambos os lados - os religiosos e os não religiosos - têm condições de levar a sério as contribuições para os temas controversos. Segundo o autor, assim garante-se a liberdade de consciência, pensamento, credo etc., ao mesmo tempo em que o Estado assegura a autonomia privada e pública - com o direito operacionalizando a tensão entre validade e facticidade. Assim, o direito constitui um poder político - e o inverso também é verdadeiro, segundo o autor - gerando um nexo que abre a possibilidade de uma instrumentalização do direito para o emprego estratégico do poder.

Para o filósofo alemão, a constituição do Estado liberal moderno basta por si mesma naquilo que tange à legitimação, uma vez que dispõe de um acervo cognitivo de argumentos independentes da tradição. Naquilo que tange ao aspecto motivacional, tem-se que o Estado não garante apenas as liberdades negativas, dessa forma, com a ideia de liberdades comunicativas, tem-se o incentivo à participação dos cidadãos e das cidadãs nos debates públicos sobre os temas comuns a todos e a todas, constituindo assim o "vínculo unificador" que estaria faltando aos Estados modernos. Sem esse aspecto de vínculo unificador de uma solidariedade, os cidadãos e as cidadãs não conseguiriam se entender como participantes com iguais direitos - que devem argumentos uns aos outros (e outras). Assim, não se pode, por exemplo, acabar com os espaços religiosos na esfera pública. A neutralidade ideológica do poder do Estado é incompatível com a generalização de uma visão de mundo secularizada, pois a neutralidade deve garantir as mesmas liberdades éticas para todos os cidadãos e as cidadãs. Assim, como afirmado por Pinzani (2009a), o pensamento habermasiano deve ser visto como um convite à prudência e à compreensão recíproca. 
Viu-se neste trabalho que para Habermas é um fardo pesado demais a ideia de que os religiosos precisam traduzir seus posicionamentos para uma linguagem neutra e racional (ou razoável). Habermas, assim, posiciona-se de maneira contrária à ideia rawlsiana de proviso. Segundo o filósofo alemão, os cidadãos e as cidadãs, muitas vezes não conseguiriam fazer a divisão artificial entre cidadãos e religiosos, eles são cidadãos-religiosos. Não se pode esperar que o Estado liberal faça com que todas as pessoas crentes fundamentem seus posicionamentos políticos deixando de lado suas convicções de vida boa, concepções de mundo, enfim, suas cosmovisões religiosas. A ideia de separação estrita entre os argumentos religiosos e não religiosos, na esfera pública, consiste em um ataque à identidade nacional dos cidadãos e das cidadãs religiosas nos Estados modernos. Os Estados não podem desencorajar a participação dos religiosos nas esferas públicas, nas quais o que conta é a força do melhor argumento.

\section{REFERÊNCIAS}

ARAUJO, L. B. L. A ordem moral moderna e a política do secularismo. Ethic@ Florianópolis, v. 10, n. 3, p. 39 - 53. 2011a. Disponível em: <https://periodicos.ufsc.br/index.php/ethic/article/view/1677-2954.2011v10n3p39/21551>. Acesso em: 14 jul.2015.

ARAUJO, L. B. L. Habermas e a religião na esfera pública: um breve ensaio de interpretação. In: PINZANI, A.; LIMA, C. M. de; VOLPATO DUTRA, D. J. (Org.). O pensamento vivo de Habermas. Uma visão interdisciplinar. Florianópolis: Nefipo, 2009a. p. 229-243.

ARAUJO, L. B. L. Pluralismo e justiça: estudos sobre Habermas. São Paulo: Edições Loyola, 2010.

BAVARESCO, A.; LIMA, F. J. G. de. A ideia rawlsiana de razão pública: Limites e alternativas a partir de Habermas. Sol Nascente - revista do centro de investigação sobre ética aplicada. Disponível em:

$<$ http://www.ispsn.org/sites/default/files/magazine/articles/N2\%20art6.pdf $>$. Acesso em: 14 jun. 2015.

COELHO, A. Uso de argumentos religiosos na esfera pública judicial: exploração de uma hipótese a partir de Jürgen Habermas. Disponível em:

〈http://www.academia.edu/4435900/Uso_de_Argumentos_Religiosos_na_Esfera_Judicial>. Acesso em: 27 jul. 2015.

FELDENS, G. O. A razão pública no Liberalismo Político de John Rawls. Perspectiva, Erechim. v. 36, n. 136, p. 61-71, dezembro/2012. Disponível em:

<http://www.uricer.edu.br/site/pdfs/perspectiva/136_302.pdf $>$. Acesso em: 01 maio 2015. 
FREIRE, W. F. A. Religião, esfera pública e pós-secularismo: o debate Rawls-Habermas acerca do papel da religião na democracia liberal. Saberes, Natal, v. 1, n.10, nov. 2014, 104134. Disponível em: 〈http://periodicos.ufrn.br/saberes/article/viewFile/5445/4917>. Acesso em: 02 abr. 2015.

HABERMAS, Jürgen. Direito e democracia: entre facticidade e validade. V. I. Tradução de Flávio Beno Siebeneichler. Rio de Janeiro: Tempo Brasileiro, 1997a.

HABERMAS, Jürgen. Direito e democracia: entre facticidade e validade. V. II. Tradução de Flávio Beno Siebeneichler. Rio de Janeiro: Tempo Brasileiro, 1997b.

HABERMAS, Jürgen. Direito e moral. Tradução de Sandra Lippert. Lisboa: Instituto Piaget, 1999.

HABERMAS, Jürgen. Fé e saber. Tradução de Fernando Costa Mattos. São Paulo: Editora Unesp, 2013.

HABERMAS, Jürgen. Mudança estrutural da esfera pública: investigações sobre uma categoria da sociedade burguesa. Tradução e apresentação de Denilson Luis Werle. São Paulo: Editora Unesp, 2014.

HABERMAS, Jürgen. Entre naturalismo e religião - estudos filosóficos. Tradução de Flávio Beno Siebeneichler. Rio de Janeiro: Tempo Brasileiro, 2007.

HABERMAS, Jürgen; RATZINGER, Joseph. Dialética da secularização: sobre razão e religião. Tradução de Alfred J. Keller. Aparecida, SP: Ideias e Letras, 2007.

MONTERO, P. Jürgen Habermas: religião, diversidade cultural e publicidade. Novos Estados, n. 84. Disponível em:

<http://novosestudos.uol.com.br/v1/files/uploads/contents/142/20090901_11_PaulaMontero p198a213_nova.pdf>. Acesso em: 07 jul. 2015.

PINHEIRO, C. M. O palco das decisões sobre o ensino da tolerância. Ethic@ - Florianópolis, v. 10, n. 3, p. 1 - 12, dez. 2011. Disponível em:

<https://periodicos.ufsc.br/index.php/ethic/article/view/1677-2954.2011v10n3p1/21549>.

Acesso: 04 abr. 2015.

PINZANI, A. Fé e saber? Sobre alguns mal-entendidos relativos a Habermas e à religião. In: PINZANI, A.; LIMA, C. M. de; VOLPATO DUTRA, D. J. (Org.). O pensamento vivo de Habermas: uma visão interdisciplinar. Florianópolis: Nefipo, 2009a. p. 211-227.

PINZANI, A. Filosofia política III. Florianópolis: Filosofia/EAD/UFSC, 2011.

PINZANI, A. Habermas. Porto Alegre: Artmed, 2009b.

PINZANI, A. O natural e o artificial. Argumentos morais e políticos contra a eugenia liberal seguindo Habermas e Foucault. Ethic@ (UFSC), Florianópolis, v. 4, n.3, p. 361-377, 2005.

PINZANI, A. Por que é necessário um Estado laico. In: SPICA, M. A.; LUJÁN 
MARTINEZ, H. (Org.). Religião em um mundo plural. Debates desde a filosofia. Pelotas: Dissertatio, 2014, p. 235-262.

RAWLS, John. A Ideia de Razão Pública Revista. In: RAWLS, John. O direito dos povos. Tradução de Luis Carlos Borges. São Paulo: Martins Fontes, 2004.

RAWLS, John. Justiça como equidade: uma reformulação. Tradução de Álvaro de Vita. São Paulo: Martins Fontes, 2003.

RAWLS, John. Justiça e democracia. Tradução de Irene A. Paternot. São Paulo: Martins Fontes, 2000a.

RAWLS, John. O liberalismo político. Tradução de Dinah de Abreu Azevedo. São Paulo: Ática, 2000b.

RAWLS, John. Uma teoria da justiça. Tradução de Almiro Pisseta e Linita M. R. Esteves. São Paulo: Martins Fontes, 2000c.

SILVEIRA, D. C. O papel da razão pública na teoria da justiça de Rawls. Filosofia Unisinos, 10(1): 65-78, jan/abr 2009. Disponível em:

$<$ http://revistas.unisinos.br/index.php/filosofia/article/view/5005/2258>. Acesso em: 16 maio 2015 .

SOUZA, A. A. Religião e Secularismo: interpretações e dissonâncias no projeto do liberalismo político. In: PINZANI, A.; LIMA, C. M. de; VOLPATO DUTRA, D. J. (Org.). O pensamento vivo de Habermas. Uma visão interdisciplinar. Florianópolis: Nefipo, 2009. p. 245-262.

VOLPATO DUTRA, D. J. Consequências da neutralização moral do procedimento jurídico em Direito e Democracia. Ethic@ Florianópolis v. 8, n. 3, p. 127-141, maio 2009. Disponível em: 〈https://periodicos.ufsc.br/index.php/ethic/article/download/16772954.2009v8n3p127/21870>. Acesso em: 08 jul. 2015.

VOLPATO DUTRA, D. J. Da função da sociedade civil em Hegel y Habermas. Utopía y PraxisLatinoamericana / Año 11, n. 35. Octubre-Diciembre, 2006, p. 55 - 65. Disponível em: 〈http://www.redalyc.org/pdf/279/27903504.pdf>. Acesso em: 15/07/2015.

VOLPATO DUTRA, D. J. Manual de filosofia do direito. Caxias do sul: EDUCS, 2008.

VOLPATO DUTRA, D. J. Moral e direito nas tannerlectures de Habermas: um modelo processual de moralização do direito. Ethic@ -Florianópolis, v. 10, n. 3, p. 13 - 37, dez. 2011. Disponível em: <https://periodicos.ufsc.br/index.php/ethic/article/viewFile/16772954.2011v10n3p13/21550>. Acesso em: 04 jun. 2015.

VOLPATO DUTRA, D. J. Razão e consenso em Habermas: a teoria discursiva da verdade, da moral, do direito e da biotecnologia. 2. ed. Florianópolis: Editora da UFSC, 2005. 
VOLPATO DUTRA, D. J.; COUTO, D. R. T. Esfera Pública: contribuições para uma atualização do diagnóstico. Problemata: R. Intern. Fil., v. 03, n. 02. (2012), p. 177-199. Disponível em:

<http://periodicos.ufpb.br/ojs/index.php/problemata/article/view/14959/8497>. Acesso em: 24 jul. 2015.

VOLPATO DUTRA, D. J.; LOIS, C. C. Modelos de moralização do direito: um estudo a partir de Jürgen Habermas. Sequência, n. 55, p. 233-252. 2007. Disponível em:

$<$ https://periodicos.ufsc.br/index.php/sequencia/article/view/15055/13726>. Acesso em:16 jul. 2015.

VOLPATO DUTRA, D. J; ROHLING, M. O Direito em Uma teoria da justiça de Rawls. In: Dissertatio [34] 63 - 89. 2011. Disponível em: < http://www2.ufpel.edu.br/isp/dissertatio/revistas/34/03.pdf > . Acesso em: 31 mar. 2015.

WERLE, D. L. A ideia de justiça e a prática da democracia. In: Novosestud. CEBRAP [online]. 2012a, n. 92, p. 153-161. ISSN 0101-3300. Disponível em: <http://www.scielo.br/pdf/nec/n92/n92a11.pdf>. Acesso em: 30 jul. 2015.

WERLE, D. L. Justiça, Liberdades básicas, e as bases sociais do auto-respeito. Ethic@ Florianópolis v.13, n.1, p. 74 - 90, jun. 2014. Disponível em:

<https://periodicos.ufsc.br/index.php/ethic/article/viewFile/16772954.2014v13n1p74/26930>. Acesso em: 16 jun. 2015.

WERLE, D. L. Liberdades Básicas, Justificação Pública e o Poder Político em John Rawls. Dissertatio [34] 183 - 207. 2011. Disponível em:

〈http://www2.ufpel.edu.br/isp/dissertatio/revistas/34/08.pdf >. Acesso em: 31 mar. 2015.

WERLE, D. L. Pluralismo e tolerância, sobre o uso público da razão em Habermas. In: PINZANI, A.; LIMA, C. M. de; VOLPATO DUTRA, D. J. (Org.). O pensamento vivo de Habermas: uma visão interdisciplinar. Florianópolis: Nefipo, 2009. p. 263-288.

WERLE, D. L. Razão e democracia - uso público da razão e política deliberativa em Habermas. Trans/Form/Ação, Marília, v. 36, p. 149-176, 2013. Edição Especial. Disponível em:

<http://www2.marilia.unesp.br/revistas/index.php/transformacao/article/view/2938/2261>. Acesso em: 18 jun. 2015.

WERLE, D. L. Tolerância, legitimação política e razão pública. Dissertatio [35] 141 - 161. 2012b. Disponível em: 〈http://www2.ufpel.edu.br/isp/dissertatio/revistas/35/07.pdf>. Acesso em: 18 jul. 2015.

ZABATIERO, J. P. T. Rumo a uma filosofia da religião em tom pós-metafísico. Diálogos com Habermas e Rorty. Horizonte, Belo Horizonte, v. 8, n. 16, p.12-32, jan./mar. 2010. 